\title{
BMJ Global Health Tuberculosis: treatment failure, or failure to treat? Lessons from India and South Africa
}

\author{
Nesri Padayatchi, ${ }^{\oplus 1,2}$ Amrita Daftary, ${ }^{3}$ Naressa Naidu, ${ }^{1,2}$ Kogieleum Naidoo, ${ }^{1,2}$ \\ Madhukar Pai ${ }^{3}$
}

\begin{abstract}
To cite: Padayatchi N, Daftary A Naidu N, et al. Tuberculosis: treatment failure, or failure to treat? Lessons from India and South Africa. BMJ Glob Health 2019;4:e001097. doi:10.1136/ bmjgh-2018-001097
\end{abstract}

\section{Handling editor Alberto L Garcia-Basteiro}

- Additional material is published online only. To view please visit the journal online (http://dx.doi.org/10.1136/ bmjgh-2018-001097).

Received 6 August 2018 Revised 2 January 2019 Accepted 4 January 2019

Check for updates

(c) Author(s) (or their employer(s)) 2019. Re-use permitted under CC BY-NC. No commercial re-use. See rights and permissions. Published by BMJ.

${ }^{1}$ Centre for the AIDS Programme of Research in South Africa, Nelson R Mandela School of Medicine, College of Health Sciences, University of KwaZuluNatal, Durban, South Africa ${ }^{2}$ Medical Research CouncilCAPRISA HIV-TB Pathogenesis and Treatment Research Unit, Doris Duke Medical Research Institute, University of KwaZuluNatal, Durban, South Africa ${ }^{3}$ McGill International TB Centre, McGill University, Montreal, Quebec, Canada

Correspondence to Dr Nesri Padayatchi; nesri.padayatchi@caprisa.org

\section{ABSTRACT}

Tuberculosis (TB) remains an enormous public health concern globally. India and South Africa rank among the top 10 high TB burden countries with the highest absolute burden of TB, and the second highest rate of TB incidence, respectively. Although the primary drivers of TB transmission vary considerably between these two countries, they do indeed share common themes. In 2017 , only $64 \%$ of the global estimated incident cases of TB were reported, the remaining $36 \%$ of 'missing' cases were either undiagnosed, untreated or unreported. These 'missing TB cases' have generated much hype for the challenges they present in achieving the End TB Strategy. Although India and South Africa have indeed made significant strides in TB control, analysis of the patient cascade of care clearly suggests that these 'missed' patients are not really missing - most are actively engaging the health system - the system, however, is failing to appropriately manage them. In short, quality of TB care is suboptimal and must urgently be addressed, merely focusing on coverage of TB services is no longer sufficient. While the world awaits revolutionary vaccines, drugs and diagnostics, programmatic data indicate that much can be done to accelerate the decline of TB. In this perspective, we compare and contrast these two national epidemics, and explore barriers, with a particular focus on the role of health systems in finding the missing millions.

Tuberculosis (TB) remains an enormous public health concern causing disease in an estimated 10 million people globally in 2017 . $^{1}$ In addition, TB is one of the top 10 causes of death worldwide, and has been the leading cause of death from a single infectious agent for the past 5 years, surpassing even that of HIV/AIDS. ${ }^{2}$ Such statistics are disconcerting given the reality that TB is not a new disease but rather one that has plagued populations for millennia, and especially since the majority of people who develop TB can be cured with a timely diagnosis and appropriate management. ${ }^{2}$ The WHO's End TB Strategy and the United Nations' Sustainable Development Goals share a common aim to end the global TB epidemic, targeting an $80 \%$ reduction in TB incidence by 2030 compared with $2015 .^{2}$
Summary box

In 2017 , only $64 \%$ of the global estimated incident cases of tuberculosis (TB) were reported worldwide, the remaining $36 \%$ of 'missing' cases were either undiagnosed, untreated or unreported.

- Analysis of the patient cascade of care in India and South Africa suggests that these 'missed' patients are not really missing; most are actively engaging the health system (public and private) but not adequately managed.

- National TB control programmes need to identify gaps and weaknesses along the entire patient care cascade, addressing barriers to appropriate diagnosis, linkages to treatment postdiagnosis while strengthening both public and private healthcare sectors, and bridging the gap between provider knowledge and practice.

- Integration of TB services within universal health coverage is critical for identifying and managing missing patients with TB.

At the current global decline in TB incidence of just $2 \%$ per annum, these targets will almost certainly be unattainable.

India and South Africa rank among the top 10 high TB burden countries. With 2.7 million new cases in 2018, India has the highest absolute burden of TB. ${ }^{1}$ With 567 new cases per 100000 population, South Africa has the second highest rate of TB incidence. ${ }^{1}$ Despite these top ranks, and collectively accounting for $31 \%$ of the world's burden of $\mathrm{TB}$, and $37 \%$ of TB deaths, ${ }^{1}$ the nature of the epidemic in South Africa and India is considerably different (table 1). In this perspective, we compare and contrast these two national epidemics, and explore barriers, with a particular focus on the role of health systems in finding the missing millions.

\section{INDIA}

India's TB epidemic is driven by poor social conditions, notably poverty, overcrowding, 
Table 1 Characteristics of the TB epidemic in India and South Africa

\begin{tabular}{|c|c|c|c|}
\hline & India & $\begin{array}{l}\text { South } \\
\text { Africa }\end{array}$ & Reference \\
\hline Incidence ${ }^{*}$ & 2740000 & 322000 & 1 \\
\hline HIV-positive TB incidence* & 86000 & 193000 & 1 \\
\hline Mortality* & 421000 & 78000 & 1 \\
\hline GDP spent on health† (\%) & 1 & 8.6 & 444 \\
\hline $\begin{array}{l}\text { Missing patients with TB } \ddagger \\
\text { (\%) }\end{array}$ & 25.7 & 5 & 45 \\
\hline $\begin{array}{l}\text { General healthcare seeking } \\
\text { in public sector }(\%)\end{array}$ & 20 & $71.2 \S$ & 46 \\
\hline $\begin{array}{l}\text { General healthcare seeking } \\
\text { in private sector }(\%)\end{array}$ & 80 & $27.4 \uparrow$ & 746 \\
\hline
\end{tabular}

*2017 data, absolute numbers.

†2015 data.

$\ddagger 2016$ data, represents share by country of the missing 4 million patients with TB globally.

$\S$ In $2017,71.2 \%$ of households indicated they would first go

to public clinics, hospitals or other public institutions when members fall ill or get injured.

IIn 2017, 27.4\% of households indicated they would first consult a private doctor, private clinic or hospital when members fall ill or get injured.

GDP, gross domestic product; TB, tuberculosis.

malnutrition and tobacco smoking. ${ }^{3} \mathrm{HIV}$ is not a major driver of the Indian TB epidemic. Government investments in health are low, at approximately $1 \%$ of the national gross domestic product. ${ }^{4}$ Despite the high TB burden, India is still reliant on old tools. For example, India only recently switched to daily drug regimens, having used intermittent regimens for decades. While rapid molecular testing is being scaled up, the country performs about 10 smears for every Xpert MTB/RIF test (which is a much superior rapid molecular test). ${ }^{35}$ The Indian healthcare system is complex and highly heterogeneous, comprising formal and informal, private and public sector providers. ${ }^{6}$ While free TB care is available in the public sector via a vertically run directly observed treatment, short course (DOTS) programme called Revised National TB Control Program (RNTCP), an estimated $50 \%$ of patients with TB are managed outside of RNTCP. ${ }^{78}$ More recent data suggest that the proportion of patients with $\mathrm{TB}$ managed in the private sector might be even higher. TB drug sales in the private market suggest that over 2.2 million patients with $\mathrm{TB}$ may be managed in the private health sector each year, which is twice the number managed in the public sector. ${ }^{9}$

Several systematic reviews highlight the magnitude and reasons for poor diagnostic and treatment outcomes in India. An average patient with TB experiences a median diagnostic delay of 55 days, after consulting almost three healthcare providers. ${ }^{6}$ Another recent systematic review of 47 studies assessed quality of TB care. In 10 of 22 studies assessing providers' knowledge, less than half of the providers surveyed had correct knowledge on the use of sputum smears for TB diagnostic purposes. ${ }^{10}$ In three of four studies evaluating self-reported practices, less than $25 \%$ of providers reported ordering a smear in patients with chest symptoms, and in 11 of 14 studies assessing treatment, less than one-third exhibited correct knowledge of the standard treatment for drug-susceptible TB. ${ }^{10}$

A recent analysis of the cascade of $\mathrm{TB}$ care in India reported that in 2013 (figure 1), 72\% of the estimated 2.7 million cases presented to government TB diagnostic services. Only $45 \%$ of estimated TB cases completed treatment. Of the $55 \%$ of cases for which treatment was not completed, half did not access diagnostic services. ${ }^{11}$ The residual $28 \%$ that did not seek care in the public sector are thought to account for much of the missing TB cases in India. A considerable proportion of these cases are treated by private sector providers. ${ }^{11}$

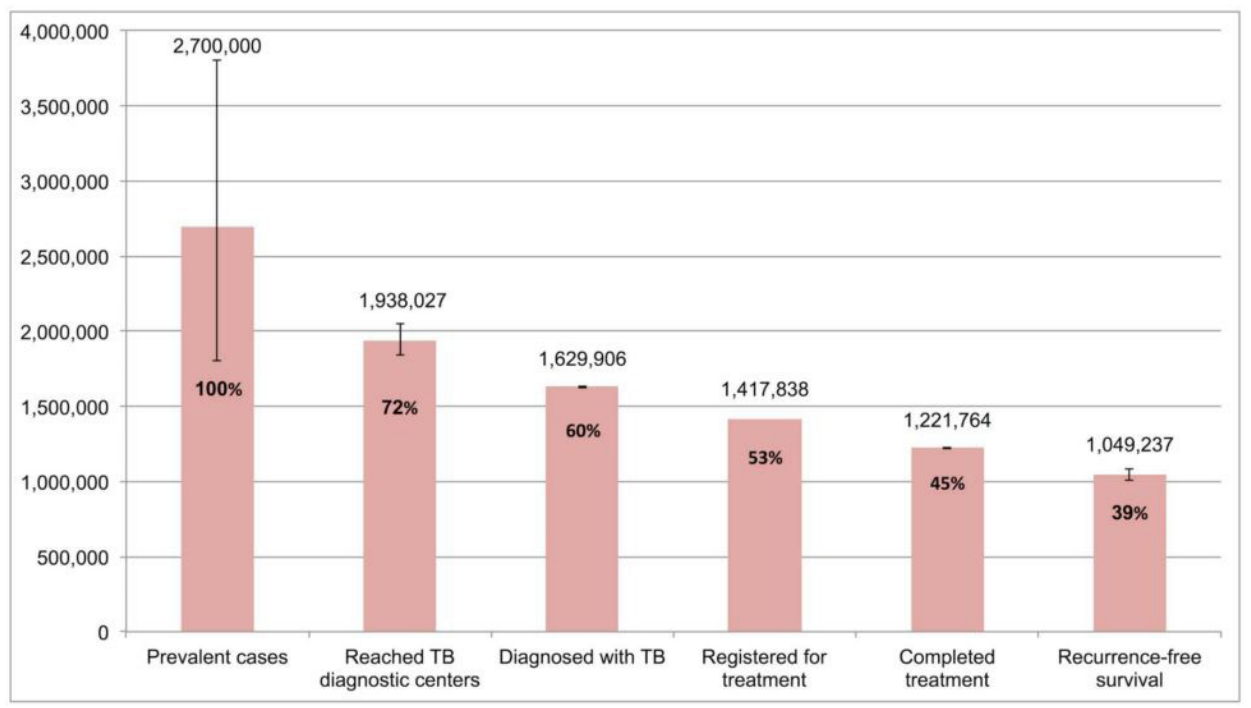

Figure 1 The cascade of care for all forms of tuberculosis (TB) in India's Revised National TB Control Program (RNTCP), 2013. Error bars depict $95 \% \mathrm{Cls}$ (Adapted from Subbaraman et $\mathrm{a} \mathbf{l}^{11}$ ). 
India's private healthcare sector is fragmented, unregulated and comprises diverse types of providers, from allopathic (or Western medicine) doctors to practitioners of complementary medicine as well as informal healthcare providers with little or no formal qualifications; quality of TB care is subsequently often suboptimal. ${ }^{3}{ }^{12}$ In a systematic review conducted by Satyanarayana et al, 11 studies reported higher levels of TB knowledge and optimal provider practices among providers in the public sector, as compared with private sector. ${ }^{10}$ Das et al further confirmed the substandard levels of care in the private sector. Using standardised (simulated) patients in large studies in multiple cities, they showed that only about a third of TB cases are correctly managed in the private sector. Their study revealed a substantial know-do gap between private providers' knowledge and practices related to TB diagnosis and treatment. ${ }^{12} 13$

Recent standardised patient studies, covering four Indian cities, provide additional insights on how Indian private pharmacies manage patients with suspected or known TB. ${ }^{14}{ }^{15}$ Correct management of the simulated patients ranged from $13 \%$ to $62 \%$, increasing with the certainty of the TB diagnosis. Antibiotics were frequently dispensed over the counter to simulated patients, with $16 \%-37 \%$ receiving such drugs across the cases. On a positive note, these studies showed that no pharmacy dispensed first-line anti-TB drugs. A common thread across all the simulated patient studies of TB in India is the low rates of TB testing by a variety of private providers, even when patients present with textbook description of suspected TB. Instead, empirical, broad-spectrum antibiotic and non-specific therapies was the norm. Thus, even when patients seek care, they get missed, or have a delayed diagnosis.

\section{SOUTH AFRICA}

South Africa shares many of India's social problems and weaknesses in the healthcare system, but, unlike India, its TB epidemic is primarily driven by its convergent HIV epidemic. In 2016, South Africa's HIV prevalence was $12.7 \%$ with an estimated antiretroviral therapy (ART) coverage of $56 \% .{ }^{16}$ South Africa had the highest number of HIV-associated TB cases worldwide in 2017, with $59.9 \%$ of incident TB cases coinfected with HIV. ${ }^{1}$ HIV-positive TB mortality accounted for $71.8 \%$ of deaths among patients with TB. ${ }^{1}$ Traditional cohort analysis reports that $75 \%$ of patients started on treatment are successfully treated. However, Naidoo et al conducted a detailed cascade of care analysis on 2013 programmatic data and found that just $53 \%$ of the estimated TB cases resulted in successful treatment completion (figure 2). ${ }^{1718}$ Their study revealed the following stepwise losses along the pathway in the public sector, from care seeking to treatment completion: $5 \%$ were not able to access $\mathrm{TB}$ tests, $13 \%$ did not receive a TB diagnosis, $12 \%$ were not initiated on treatment and $17 \%$ failed to successfully complete treatment. ${ }^{18}$

The small percentage of cases unable to access diagnostic services in South Africa is a reflection of the extensive network of free primary healthcare facilities (mostly run by nurses) in the country. ${ }^{18}$ However, the losses reported along the patient cascade of care are a reflection of weak health systems. In fact, the findings of numerous studies have alluded to diagnostic delay or poor implementation of guidelines, reinforcing the importance of health systems strengthening within the realm of TB control. In 2015, five years after the incorporation of the recommendation that TB-HIV coinfected patients initiate ART irrespective of CD4 count, 15.5\% of patients with TB-HIV did not initiate ART, ${ }^{19}$ only $38 \%$

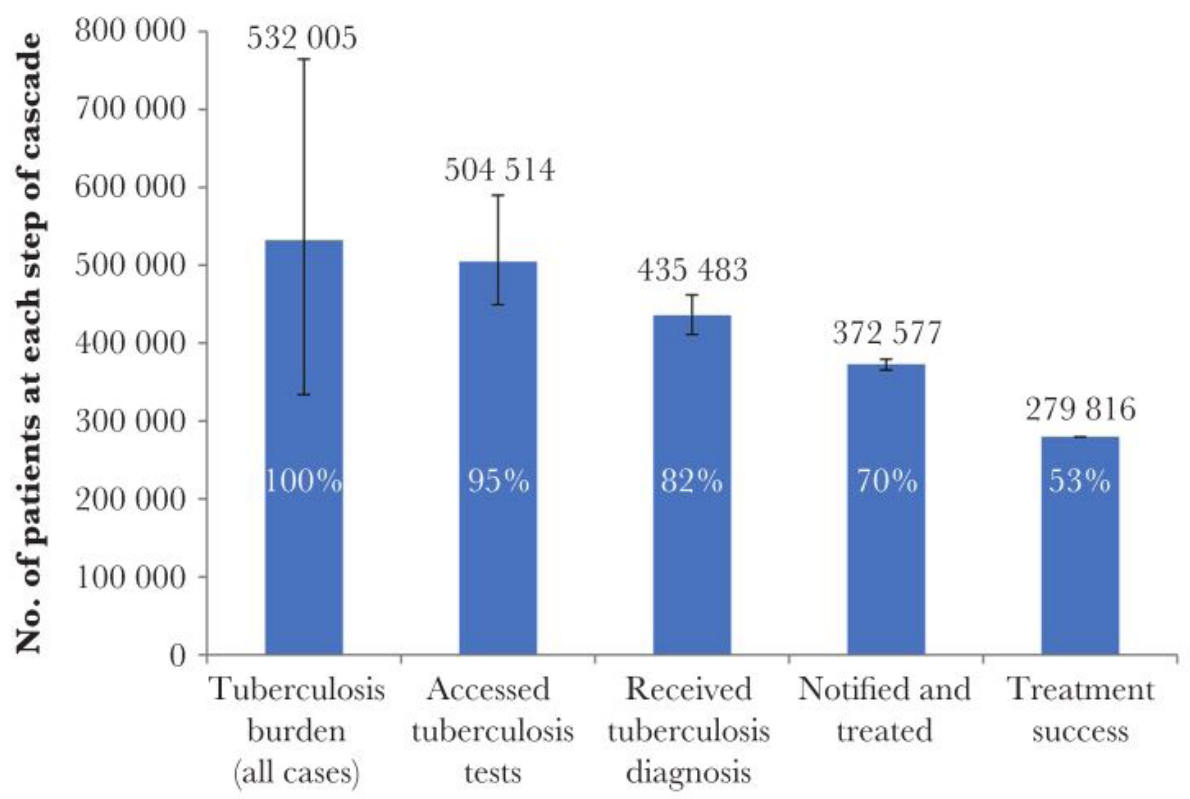

Figure 2 The cascade of care for all forms of tuberculosis in South Africa, 2013. Error bars depict 95\% Cls (Adapted from Naidoo et $a l^{18}$ ). 
of newly enrolled HIV-positive patients received isoniazid preventive therapy (IPT) in $2015 .{ }^{20}$ In 2013 , the median time to treatment initiation among new rifampicin-resistant patients with TB was 22 days, despite the introduction of Xpert MTB/RIF in November 2010, an assay that accurately detects rifampicin resistance in just 2 hours. ${ }^{21}$ Indeed, Qin et al reported that less than $60 \%$ of individuals with presumptive TB were tested with Xpert MTB/ RIF while the remainder received less reliable smear microscopy. ${ }^{22}$ Such deviations from diagnostic algorithms may partially account for the $13 \%$ of TB cases lost between TB testing and diagnosis in the patient cascade of care. $^{18}$

Furthermore, general management of patients presenting with classic TB symptoms appears to be weak. Kweza et al estimated that primary healthcare clinics, which are mostly run by qualified nurses, miss $62.9 \%-$ $78.5 \%$ of patients with TB seeking healthcare for TB-related symptoms. ${ }^{23}$ Similarly, Claassens et al reported that only $8 \%$ of individuals presenting for TB-related symptoms were screened for TB and only $3 \%$ of individuals presenting with TB-related symptoms but seeking healthcare for alternative reasons were screened at two primary healthcare facilities in Cape Town. ${ }^{24}$ Chihota $e t$ al found that only $22 \%$ of individuals with TB-related symptoms were requested to provide a sputum sample for $\mathrm{TB}$ testing. ${ }^{25}$

A recent simulated patient study from South African primary health clinics in two provinces showed that only $43 \%$ of interactions resulted in simulated patients receiving a TB sputum test and being offered an HIV test. TB sputum tests were conducted routinely $(84 \%)$ while HIV tests were offered less frequently $(47 \%) .{ }^{26}$ The 11 country-patient pathways analysis shows that nearly one-third of South Africans seek initial care outside the public system. Private providers are less likely to order a sputum test and patients accessing private care experience longer diagnostic delays. ${ }^{67-31}$ The findings of these studies reveal the magnitude of missed opportunities in the patient cascade of care that may be fuelling disease transmission.

\section{COMMON THEMES FROM INDIA AND SOUTH AFRICA}

The cascade of care analysis in both India and South Africa shows that a quarter of cases that reached government diagnostic centres were not diagnosed, or successfully diagnosed and lost to follow-up prior to TB treatment initiation. ${ }^{1118}$ Using a transmission model, a recent study in South Africa found that active case finding and loss to pretreatment follow-up were the two most effective interventions with the potential to effect a considerable impact on the TB burden. However, given the current structure of the healthcare system, reducing pretreatment loss to follow-up was predicted to be more easily achievable than active case finding,$^{32}$ due to funding and human resource constraints. ${ }^{33}$ Furthermore, data from a recent study have indicated that current approaches to active case finding have yielded limited impact, failing to produce the expected results. In fact, the ZambiaSouth Africa TB and AIDS Reduction (ZAMSTAR) study conducted in Zambia and South Africa found that expanded active case finding had no impact on either population level or paediatric TB incidence. ${ }^{34}$

The patient cascade of care however shows that a substantial percentage of cases engage with the public health sector revealing a major opportunity for health systems strengthening. The high burden of disease, increasing drug resistance, human resource constraints, ageing infrastructure, poor infection control practices, slow HIV/TB integration, inadequate training of healthcare workers, centralised services, poor management of the healthcare system at all levels, inadequate understanding of patient needs and a lack of empowerment of patients are just some of the myriad of barriers facing National Tuberculosis Programs (NTP) in addressing programmatic challenges. ${ }^{18} 33$ Increasing case detection, by upscaling rapid molecular testing particularly in India and improving compliance to diagnostic algorithms in South Africa, accelerating the time to treatment initiation and enhancing linkage to care are however essential in retaining these patients. ${ }^{11}$ Engaging the private sector to improve quality of TB care is vital to both countries, but particularly critical for India, where the private health sector dominates. To facilitate public-private mix interventions, a road map with clear action points has been recently published by WHO, Stop TB Partnership, and other stakeholders. ${ }^{35}$

India has made significant strides in TB control by rapidly scaling up $\mathrm{TB}$ services, prohibiting the use of inaccurate serological tests and introducing mandatory notification of all TB cases. ${ }^{3}$ The Indian government has recently published an ambitious National Strategic Plan (NSP) to end TB by $2025 .{ }^{36}$ However, achieving the NSP goals will require strengthening both public and private healthcare sectors, bridging the gap between provider knowledge and practice and backing political commitments with tangible funding and investments. ${ }^{37}$

Similarly, South Africa has published its NSP for TB and HIV ${ }^{38}$ and made colossal investments, managing the largest ART and IPT programmes globally, leading the rollout of Xpert MTB/RIF, adopting novel and repurposed drugs into clinically proven treatment regimens while developing ambitious and comprehensive policy guidelines for the management of TB. In fact, South Africa is the largest user of both Xpert MTB/RIF and bedaquiline. However, new tools alone are insufficient. Health system issues such as addressing diagnostic delay, improving adherence to diagnostic algorithms and amplifying TB screening and testing will prove critical to enhancing the impact of new tools. Recognising this, the South African government recently launched a quality improvement (QI) programme to address the major gaps identified in the cascade of care analyses. ${ }^{39}$

Early case detection and appropriate treatment is fundamental to TB control, the delay of which allows 
for disease progression, increases the risk of morbidity and mortality and perpetuates community-driven transmission. Importantly, in 2017 , only $64 \%$ of the estimated incident cases of $\mathrm{TB}$ were reported, the remaining $36 \%$ of 'missing' cases were either undiagnosed, untreated or unreported. ${ }^{1}$ The 'missing TB cases' have generated much hype for the challenges they present in achieving the End TB Strategy. But evidence from India and South Africa clearly suggests that these 'missed' patients are not really missing-most are actively engaging the health system (predominantly private health system in India, and predominantly public health system in South Africa) ${ }^{40}$ The system, however, is failing to appropriately manage them. In short, quality of TB care is suboptimal and must urgently be addressed. ${ }^{41}$ Merely focusing on coverage of TB services is no longer sufficient, as emphasised by the recent Lancet Global Health Commission on High Quality Health Systems. ${ }^{42}$

Forty years after Alma-Ata, nearly half the world's population lacks access to essential health services. To address this crisis, countries must commit to universal health coverage (UHC).$^{43}$ A strong primary healthcare system is the backbone of UHC. However, as reviewed earlier, TB is often missed by primary care providers in both public and private sectors. So, a big challenge for the TB field is the need to rethink the traditional vertical TB care delivery model, and integrate TB care within UHC. While the vertical approach has been helpful in ensuring donor funding and technical expertise, the model's limitation has been exposed by the fact that nearly $40 \%$ of patients with TB are missing in the DOTS system.

\section{CONCLUSION}

TB control programme monitoring must go beyond the traditional measures of success such as effective treatment. NTPs need to identify gaps and weaknesses along the entire patient care cascade and using the science of QI to address barriers to appropriate diagnosis and linkages to treatment postdiagnosis. ${ }^{17}$ Indeed, ending the TB epidemic will require rapid scientific advances: innovative diagnostic tools, new drugs and an effective TB vaccine. However, while the world awaits these revolutionary developments, programmatic data indicate that much can be done to accelerate the decline of TB by strengthening health systems and improving quality of care.

Contributors All authors contributed equally to the writing of this manuscript.

Funding This work was supported by the South African Medical Research Council. NP, NN and KN are supported by the Centre for the AIDS Programme of Research in South Africa (CAPRISA). AD is supported by a salary award from Fonds de recherche du Québec-Santé (FRQS). MP is supported by a Canada Research Chair award.

Competing interests None declared.

Patient consent for publication Not required.

Provenance and peer review Not commissioned; externally peer reviewed.

Data sharing statement № additional data are available.
Open access This is an open access article distributed in accordance with the Creative Commons Attribution Non Commercial (CC BY-NC 4.0) license, which permits others to distribute, remix, adapt, build upon this work non-commercially, and license their derivative works on different terms, provided the original work is properly cited, appropriate credit is given, any changes made indicated, and the use is non-commercial. See: http://creativecommons.org/licenses/by-nc/4.0/.

\section{REFERENCES}

1. World Health Organization. Global tuberculosis report 2018. Geneva: World Health Organization, 2018.

2. World Health Organization. Global tuberculosis report 2017. Geneva: World Health Organization, 2017.

3. Pai M, Daftary A, Satyanarayana S. TB control: challenges and opportunities for India. Trans R Soc Trop Med Hyg 2016;110:158-60.

4. Goel A. Fixing the broken bones of India's health system: al Jazeera America, 2015. Available: http://america.aljazeera.com/opinions/ 2015/9/fixing-the-broken-bones-of-indias-health-system.htm [Accessed 11 Jul 2018]

5. Cazabon D, Suresh A, Oghor C, et al. Implementation of Xpert MTB/RIF in 22 high tuberculosis burden countries: are we making progress? Eur Respir J 2017;50:1700918.

6. Sreeramareddy CT, Qin ZZ, Satyanarayana S, et al. Delays in diagnosis and treatment of pulmonary tuberculosis in India: a systematic review. Int J Tuberc Lung Dis 2014;18:255-66.

7. Satyanarayana S, Nair SA, Chadha SS, et al. From where are tuberculosis patients accessing treatment in India? Results from a cross-sectional community based survey of 30 districts. PLoS One 2011;6:e24160

8. Wells WA, Ge CF, Patel N, et al. Size and usage patterns of private TB drug markets in the high burden countries. PLOS One 2011;6:e18964

9. Arinaminpathy N, Batra D, Khaparde S, et al. The number of privately treated tuberculosis cases in India: an estimation from drug sales data. Lancet Infect Dis 2016;16:1255-60.

10. Satyanarayana S, Subbaraman R, Shete P, et al. Quality of tuberculosis care in India: a systematic review. Int J Tuberc Lung Dis 2015;19:751-63.

11. Subbaraman R, Nathavitharana RR, Satyanarayana S, et al. The tuberculosis cascade of care in India's public sector: a systematic review and meta-analysis. PLoS Med 2016;13:e1002149.

12. Das J, Kwan A, Daniels B, et al. Use of standardised patients to assess quality of tuberculosis care: a pilot, cross-sectional study. Lancet Infect Dis 2015;15:1305-13.

13. Kwan A, Daniels B, Saria V, et al. Variations in the quality of tuberculosis care in urban India: a cross-sectional, standardized patient study in two cities. PLoS Med 2018;15:e1002653.

14. Miller R, Goodman C. Do chain pharmacies perform better than independent pharmacies? Evidence from a standardised patient study of the management of childhood diarrhoea and suspected tuberculosis in urban India. BMJ Glob Health 2017;2:e000457.

15. Satyanarayana S, Kwan A, Daniels B, et al. Use of standardised patients to assess antibiotic dispensing for tuberculosis by pharmacies in urban India: a cross-sectional study. Lancet Infect Dis 2016:16:1261-8.

16. World Health Organization. South Africa HIV country profile, 2016. Available: http://www.who.int/hiv/data/Country_profile_South_Africa. pdf?ua $=1$ [Accessed 15 Nov 2018].

17. Chin DP, Hanson CL. Finding the missing tuberculosis patients. $J$ Infect Dis 2017;216(Suppl 7):S675-8.

18. Naidoo $P$, Theron G, Rangaka MX, et al. The South African tuberculosis care cascade: estimated losses and methodological challenges. J Infect Dis 2017;216(suppl_7):S702-S713.

19. Health Systems Trust. In: Massyn N, Peer N, English R, eds. District health barometer 2015/16. Durban: Health Systems Trust, 2016.

20. World Health Organization. Global tuberculosis report 2016. Geneva: World Health Organization, 2016.

21. Cox H, Dickson-Hall L, Ndjeka N, et al. Delays and loss to followup before treatment of drug-resistant tuberculosis following implementation of Xpert MTB/RIF in South Africa: a retrospective cohort study. PLoS Med 2017;14:e1002238.

22. Qin ZZ, Pai M, Van Gemert W, et al. How is Xpert MTB/RIF being implemented in 22 high tuberculosis burden countries? Eur Respir $J$ 2015;45:549-54.

23. Kweza PF, Van Schalkwyk C, Abraham N, et al. Estimating the magnitude of pulmonary tuberculosis patients missed by primary health care clinics in South Africa. Int J Tuberc Lung Dis 2018;22:264-72. 
24. Claassens MM, Jacobs E, Cyster E, et al. Tuberculosis cases missed in primary health care facilities: should we redefine case finding? Int $J$ Tuberc Lung Dis 2013;17:608-14.

25. Chihota VN, Ginindza S, McCarthy K, et al. Missed opportunities for TB investigation in primary care clinics in South Africa: experience from the XTEND trial. PLoS One 2015;10:e0138149.

26. Christian C, Gerdtham U-G, Hompashe D, et al. Measuring quality gaps in TB screening in South Africa using standardised patient analysis. Int J Environ Res Public Health 2018;15:E729:729.

27. Hazarika I. Role of private sector in providing tuberculosis care: evidence from a population-based survey in India. $J$ Glob Infect Dis 2011;3:19-24.

28. Meintjes G, Schoeman H, Morroni C, et al. Patient and provider delay in tuberculosis suspects from communities with a high HIV prevalence in South Africa: a cross-sectional study. BMC Infect Dis 2008;8:72.

29. Skordis-Worrall J, Hanson K, Mills A. Confusion, caring and tuberculosis diagnostic delay in Cape Town, South Africa. Int $J$ Tuberc Lung Dis 2010;14:171-80.

30. Van Wyk SS, Enarson DA, Beyers N, et al. Consulting private health care providers aggravates treatment delay in urban South African tuberculosis patients. Int J Tuberc Lung Dis 2011;15:1069-76.

31. Zuma T, Wight D, Rochat T, et al. The role of traditional health practitioners in rural KwaZulu-Natal, South Africa: generic or mode specific? BMC Complement Altern Med 2016;16:304.

32. Knight GM, Dodd PJ, Grant AD, et al. Tuberculosis prevention in South Africa. PLoS One 2015;10:e0122514.

33. Churchyard GJ, Mametja LD, Mvusi L, et al. Tuberculosis control in South Africa: successes, challenges and recommendations. S Afr Med J 2014;104(3 Suppl 1):244-8.

34. Ayles H, Muyoyeta M, Du Toit E, et al. Effect of household and community interventions on the burden of tuberculosis in southern Africa: the ZAMSTAR community-randomised trial. Lancet 2013;382:1183-94.
35. World Health Organization. Public-private mix for TB prevention and care: a roadmap. Geneva: World Health Organization, 2018.

36. Ministry of Health with Family Welfare. National strategic plan for tuberculosis elimination 2017-2025. New Delhi: Ministry of Health with Family Welfare, 2017.

37. Pai M, Bhaumik S, Bhuyan SS. India's plan to eliminate tuberculosis by 2025: converting rhetoric into reality. BMJ Glob Health 2016;2:e000326.

38. South Africa's national strategic plan for HIV, Tb and STIs 20172022. Available: http://sanac.org.za/wp-content/uploads/2017/05/ NSP_FullDocument_FINAL.pdf [Accessed $11 \mathrm{Jul} 2018$ ].

39. Pai M. The Science of Improvement: TB Cannot Afford to Lag Behind, 2018. Available: https://naturemicrobiologycommunity. nature.com/users/20892-madhukar-pai/posts/32859-science-ofimprovement-tb-cannot-afford-to-lag-behind [Accessed 11 Jul 2018]

40. World Health Organization. Engaging private health care providers in $T B$ care and prevention: A landscape analysis. Geneva: World Health Organization, 2018.

41. Cazabon D, Alsdurf H, Satyanarayana S, et al. Quality of tuberculosis care in high burden countries: the urgent need to address gaps in the care cascade. Int J Infect Dis 2017;56:111-6.

42. Kruk ME, Gage AD, Arsenault C, et al. High-quality health systems in the sustainable development goals era: time for a revolution. Lancet Glob Health 2018;6:e1196-252.

43. Ghebreyesus TA. All roads lead to universal health coverage. Lancet Glob Health 2017;5:e839-40.

44. National Department of Health. National health insurance for South Africa - Towards Universal health coverage. Republic of South Africa: National Department of Health, 2015.

45. World Health Organization, 2016. Author. Available: http://www.who. int/tb/country/data/download/en/ [Accessed 11 Jul 2018].

46. Statistics South Africa. General Household Survey, 2017. Pretoria: Statistics South Africa, 2017. 